\title{
Experimental Characterization of Recycled Aggregate Concrete
}

\author{
Khaoula NAOUAOUI ${ }^{1, a}$, Azzeddine BOUYAHYAOUI ${ }^{1}$ and Toufik CHERRADI ${ }^{1}$ \\ ${ }^{1}$ Mohammadia School of engineers - Mohamed V University - Agdal - MOROCCO
}

\begin{abstract}
The field of construction is evolving rapidly over the last decade. This is justified by the evolution of human activity in various fields mainly tourism, industry ... and the aging of several buildings which implies a renovation or a demolition / re-construction. These construction activities involve a large need for aggregates for new construction and a large tonnage of waste from demolitions.

In order to remedy this, various stakeholders in the field (suppliers, cement works, research centers, etc.) have valued recycled aggregate concrete (RAC).

Recycled aggregates concrete is considered a new type of concrete based on the use of aggregates retrieved from the demolished structures instead of natural aggregates. This replacement affects, for sure, the characteristics of the concrete produced specially the mechanical properties.

Developed countries have made a great progress in normalizing the use of recycled aggregates (RA) in concrete implementation as a result of many studies done since 80 's. In Morocco, recycled aggregates do not have any specific standards, and is used mainly in roads and pavements construction. Even if it's not normalized this use is not recent, in 1999 during the rehabilitation of the expressway road of Casablanca which was severely damaged on both channels, the authorities have opted for the reuse of aggregates instead of reloading the existing pavement with a new one.

The study is based on the use of recycled concrete crushed from an old building in Rabat- Morocco as aggregates and compared it with naturel aggregates from Morocco to determinate the effect of this replacement on several characteristics of concrete.

This article is aiming to investigate experimentally the effect of RA in concrete using different replacement levels, different types of adjuvant and different percentages of it.

The results show that over $30 \%$ of replacement, the compressive strength decreases considerably for basic concrete. In order to increase the compressive strength for the RAC with a percentage of replacement over $50 \%$, we used different types of additives (Plasticizer, superplasticizer and new generation superplasticizer) and different percentage of it $(0.5 \%, 1 \%$ and $1.5 \%)$ : We concludes that, for our case, the add of plasticizer gives the best result and that the $1 \%$ replacement is the optimum percentage.

The tests done on RCA made by plasticizer with different replacement level confirm the results without plasticizer: Compressive strength decreases when the replacement percentage increases.
\end{abstract}

\section{Introduction}

The census of the production of construction and demolition waste generated exceeds a billion of ton per year in the world. In 2010, the construction waste produced in the USA from building demolition alone is estimated to be 123 million tons per year, on the other hand the EU had generated about 850 millions tones.

This is becoming a considerable problem especially for the environment and the health of humanity due to the most common way of managing it: Deposit in landfills. Thus, in developed countries, laws have been brought into practice to restrict this waste: in the form of prohibitions or special taxes existing for creating waste areas.

The alternative method to this unsustainable managing, and to help decreasing the consumption of natural aggregate, is the use of recycle concrete

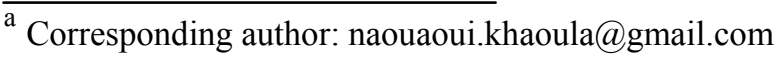

aggregates instead of natural ones as the base of concrete industry.

The main purpose of this work is to determine the basic properties of RAC depending on the coarse recycled aggregate content, and to compare them to the properties of concrete made with natural aggregate (NAC) - control concrete.

\section{Basic Properties of Concrete with Recycled Concrete Aggregate}

The last decade knew a big movement regarding recycled aggregate concrete. Many studies are done in all of the developed countries in order to showcase the concrete based on the use of recycled concrete in replacement of natural ones.

This characterization differs from one country to another, from one study to another depending on the 
research targets: mechanical, thermal, sustainable characterization...

The results of these studies are not similar. This is justified by the origin of these aggregates and what is concretized by mechanical, thermal and conditioned points of view: zone near the sea, alkaline attack ... In addition, a major factor that affects is the crushed and the treatment process of aggregates.

These differences automatically affect the characteristics of aggregates and concrete. You will find below the summaries of the majority of the studies:

- increased drying shrinkage up to $50 \%[1,2]$;

- water absorption increased up to $50 \%[3,4]$;

- decreased compressive strength up to $25 \%$ [3, 5, 6, 7];

- decreased splitting and flexural tensile strength up to $10 \% \quad[3,6,7]$;

- decreased modulus of elasticity up to $45 \%[5,6,7]$.

\section{Results of tests on Concrete with Recycled Concrete Aggregate}

The aim of our study is to characterize a concrete done by crushed recycled aggregates from an old construction is Rabat-Morocco.

Our experimental program followed the process below:

- Characterization of the aggregates after crushing them;

-Determination of compressive strength of concrete based on this aggregates;

- Determination and comparison of compressive strength of concrete based on this aggregates using different adjuvants, different percentage of these adjuvant.

\subsection{Recycled aggregates properties}

Our laboratory tests have allowed us to draw these conclusions:

- The shape of the granulometric curves for GR1 ( recycled aggregates 5-12,5) and GN1 ( natural aggregates 5-12,5) is almost identical, at the $10 \mathrm{~mm}$ opening, for example, the percentage of the cumulative sieve of GN1 is almost $50 \%$ and the GR1 is $60 \%$;

- The distribution of the various sizes of GR2 (recycled aggregates 12, 5-25) and GN2 (recycled aggregates 12, 525) aggregates is different; this distribution is favorable for GR2. It allows to have less vacuum and pore in our concrete and to compensate for the defects of the recycled aggregates;

- The absolute density calculated for the recycled aggregates is 2, 48. The chosen one for our study is 2500 $\mathrm{kg} / \mathrm{m} 3$. It's justified by the fact that our aggregates are based on concrete;

- The calculated water content for GR1 is $1,49 \%$ and for GR2 is $4,32 \%$. This different is predictable due to the different between GR1 and GR2 sizes which allow GR2 to keep more water in these pores;

- The calculated water absorption rate for GR 1 is 11 , $11 \%$ and for GR2 is $9,4 \%$. This different is predictable due to the fact that the contact surface of GR1 is greater than that of GR2.

\subsection{Recycled aggregates concrete properties:}

The concrete formulation chosen is an ordinary concrete with an fc28 (compressive strength at 28days) of 25MPA, and an average slump of $7 \mathrm{~cm}$. This formulation corresponds to a basic concrete used in elements of ordinary construction not subjected to extraordinary efforts or effects.

The formulation was done using the dreux gorisse method.

In order to compare the replacement effect of natural aggregates with recycled aggregates, several replacement ratios were studied: $0 \%-20 \%-50 \%-75 \%-100 \%$.

The compressive strength test is done using a standardized method based on the crush of $16 * 32$ cylindrical test specimens which have being left in wet cure.

The result of this test is us follow:

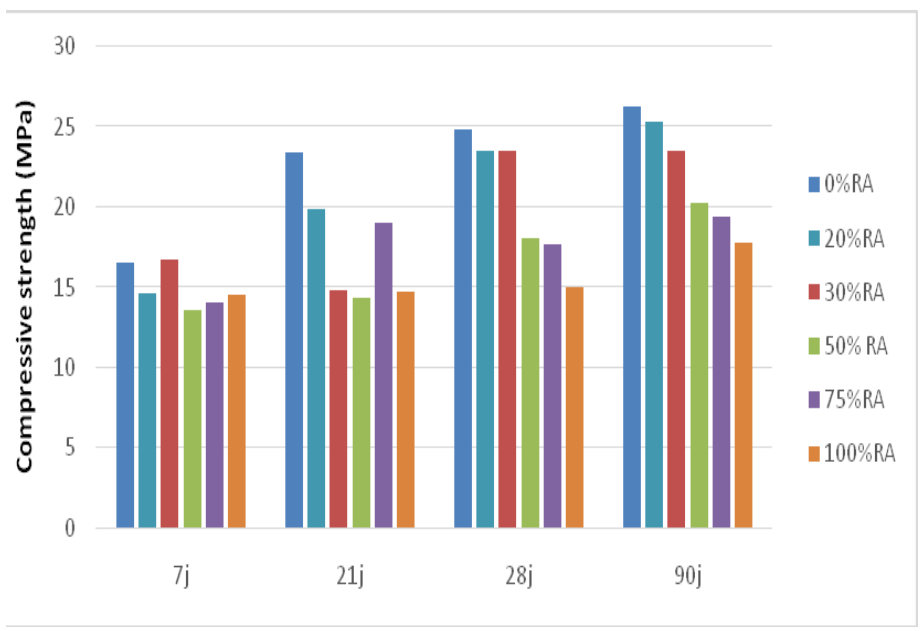

For this first part of our experimental studies, we wanted to know the effect of the replacement level on the compressive strength.

Our results match the majority of other research's experimental tests: the compressive strength decreases with the increase of the percentage level.

The percentage of decrease in 28 days is detailed in the Table 1 .

Table1. Compressive Strength test results.

\begin{tabular}{|l|l|l|l|l|l|l|}
\hline & $\begin{array}{l}0 \% \\
\text { RA }\end{array}$ & $\begin{array}{l}20 \% \\
\text { RA }\end{array}$ & $\begin{array}{l}30 \% \\
\text { RA }\end{array}$ & $\begin{array}{l}50 \% \\
\text { RA }\end{array}$ & $\begin{array}{l}75 \% \\
\text { RA }\end{array}$ & $\begin{array}{l}100 \% \\
\text { RA }\end{array}$ \\
\hline \% of RA & 0 & 20 & 30 & 50 & 75 & 100 \\
\hline $\begin{array}{l}\text { CS at 28 } \\
\text { days }\end{array}$ & 24,8 & $\begin{array}{l}23,5 \\
5\end{array}$ & 23,5 & $\begin{array}{l}18,0 \\
5\end{array}$ & 17,7 & 15 \\
\hline $\begin{array}{l}\% \text { of } \\
\text { decrease / } \\
\text { the targeted } \\
\text { value } \\
\text { (25MPA }\end{array}$ & 0.8 & 5.8 & 6 & 27.8 & 29.2 & 40 \\
\hline
\end{tabular}

The conclusion of this part of tests is that beyond 50\%, this formulation shouldn't' been adopted and that an improvement in quality is required to adopt this type of concrete.

The second step for the comparison study is to add several types of adjuvants to our formulation to 
determinate to effect of this add on the compressive strength.

We used three types of additives from SIKA with a percentage of $1 \%$. :

- Plasticizer: BV 40;

- Superplasticizer: Tempo $10 \mathrm{~m}$;

- New generation superplasticizer: SFR.

The concrete is made by $50 \%$ recycled aggregates.

Compression tests are done at 7 days (short time) and 28 days (reference value for sizing) and the results are detailed in the Table 2.

Table 2. Compressive Strength test results for concrete with different adjuvants.

\begin{tabular}{|l|l|l|l|l|}
\hline \% of RA & $\begin{array}{l}\text { Type of } \\
\text { adjuvant }\end{array}$ & $\begin{array}{l}\text { \% of } \\
\text { adj }\end{array}$ & $\begin{array}{l}\text { CS at 7 } \\
\text { days }\end{array}$ & $\begin{array}{l}\text { CS at 28 } \\
\text { days }\end{array}$ \\
\hline \multirow{3}{*}{50} & BV40 & \multirow{2}{*}{$1 \%$} & 19,87 & 22,63 \\
\cline { 2 - 2 } \cline { 5 - 5 } & SFR & & 11,50 & 16,65 \\
\cline { 2 - 2 } \cline { 5 - 6 } & Tempo 10 M & & 17,47 & 21,45 \\
\hline
\end{tabular}

The plasticizer gives a better resistance as well as the superplasticizer.

The new generation superplasticizer gives a lower result. This can be interpreted as a bad interaction with the aggregates and their cement paste attached.

Other tests are done to choose the best replacement percentage for the adjuvant. These results prove that $1 \%$ is the best replacement percentage.

The results are detailed below in Table 3 :

Table 3. Compressive Strength test results for concrete with different percentage of the adjuvant.

\begin{tabular}{|l|l|l|l|l|}
\hline $\begin{array}{l}\% \\
\text { RA }\end{array}$ & $\begin{array}{l}\text { Type of } \\
\text { adjuvant }\end{array}$ & $\%$ of adj & $\begin{array}{l}\text { CS at 7 } \\
\text { days }\end{array}$ & $\begin{array}{l}\text { CS } \\
\text { at 28 } \\
\text { days }\end{array}$ \\
\hline \multirow{2}{*}{50} & \multirow{2}{*}{$\begin{array}{l}\text { Tempo } \\
\text { M } 10\end{array}$} & $0,5 \%$ & 14,35 & 19,90 \\
\cline { 3 - 6 } & & $1,0 \%$ & 17,47 & 21,45 \\
\cline { 3 - 5 } & & $1,5 \%$ & 12,87 & 16,03 \\
\hline
\end{tabular}

After choosing the best additive and the most adequate percentage of it, we did various mixed with different quantities of recycled aggregates in the concrete formulation.

The results were similar to those without additives: compression decreases with increasing percentage of recycled aggregates.

Interpretation of the test results: The characterization of recycled aggregate concrete can not be generalized due to the difference between the characteristics of the original concrete. The data of formulation and characterization of our original concrete are unknown.

Our tests have shown that for the formulation that has been developed, the replacement percentage of natural aggregates by recycled aggregates must not exceed $50 \%$. If we want to exceed this replacement value, a use of an adjuvant is necessary. A plasticizer / or superplasticizer with a rate of $1 \%$ is recommended. The behavior of a recycled aggregate concrete with additives

from the mechanical point of view is similar to a concrete without adjuvant.

\section{Discussion about the durability characterization of Concrete with Recycled Concrete Aggregate}

One of the important characteristics of concrete is durability, the behavior of concrete in the long term.

In our study, this characterization is difficult: Our study does not focus on an exact type of building so the sustainability indicator is not fixed.

In this paragraph a summary of the studies made by other researchers in this field.

Abbas and Al (2009) [8] conducted a study based on the comparison between conventional concrete, RCA concrete and a new one based on the Equivalent Mortar volume "EMV" method which guarantees that the volume of total mortar (residual and new) in concrete produced with RCA will be equivalent to that in the conventional concrete.

The general conclusion of this research is:

- RCA-concrete mixes proportioned by the conventional mix designmethod or by the EMV method has strong resistance against freeze-and thaw action;

- EMV method produces concrete with stronger resistance against freeze-and-thaw action compared to RCA-concrete proportioned by conventional mix design method;

- The measured acid soluble initial chloride concentration of the RCA-concrete proportioned by the EMV method was found to be lower than the limits specified by the current standards.

The apparent chloride diffusion coefficients for all RCA-concretespecimens made of mixtures proportioned by the EMV methodwere found to be of the same order of magnitude as the specimensmade of conventional structural-grade concrete;

- The resistance to chloride penetration of RCAconcrete specimensmade of mixtures proportioned by the EMV method was improved by the addition of supplementary cementitious materials (fly ash or bfs) as partial replacement for ordinary portlandcement. The application of the EMV method in conjunction with the addition of supplementary cementitious materials yields concrete with high resistance to chloride penetration;

- The carbonation depths of RCA-concrete with and without supplementary cementitious materials fall in the expected range for structural-grade conventional concrete. RCA-concrete specimens without supplementary cementitious materials showed the lowest level of carbonation, followed by specimens containing bfs and fly ash, respectively.

G.Andreu and E.Miren [9] conducted an experimental analysis of properties of high performance recycled aggregate concrete. 
This recycled concretes showed very similar sorptivity values to those of conventional concrete due to very low water-cement ratio used in concrete mixes.

According to the resistance of chloride-ion penetration, the concrete produced using up to $50 \%$ of recycled aggregates (obtained from crushing concrete with minimum $40 \mathrm{MPa}$ ) achieved similar durability properties to those of high performance conventional concrete.

This study recommend to employ mineral admixtures to recycled concretes mixes in order to produce durable High Performance concrete and concluded that recycled aggregates sourced from original medium-high strength concrete can be successfully used in HPC.

As a summary to this studies and many others that will be shown below durability and the long-term performance as part of the main characteristics for the use or not of a concrete formulation.

Chloride conductivity, oxygen and water permeability, carbonation depth, alkaline aggregate reaction, sulphate resistance, shrinkage and creep performance, abrasion resistance and freeze resistance are some of the parameters that could be used as durability and long-term performance indicators of concrete material.

In general, concrete made with RA showed less durability due to high pore volume which led to high permeability and water absorption. High water absorption is due to cement paste adhered on the aggregate surface. However, this can be countered by achieving saturated surface dry (SSD) conditions before mixing. This might not be practical in some cases of mass production.

Therefore, aggregate absorption can be accounted for during the mix design stage by adjusting the mixing water that will be absorbed by the recycled aggregate. Surface coating was another approach to control absorption and improve properties [10,11,12,13].

As detailed previously and in agreement with many research efforts, the use of supplementary cementitious materials as a replacement for cement or addition by weight can improve concrete durability due to improvement of pore structure and reduction of the volume of macro pores.

Fly ash (25-35\%), silica fume (10\%) and groundgranulated blast-furnace slag (up to $65 \%$ ) are the most commonly SCM which are used to improve concrete strength and durability properties [14-15].

\section{Conclusion}

As a conclusion, the main of this study is to determinate the characteristics of concrete made using recycled aggregates.

For our case, the origin of our crushed concrete is unknown so we couldn't use its characteristics as a base of our formulation and we limited ourselves to the experimental study.

The results of it are summarized as: the effect of the mortar attached decreases the mechanical and durability properties.
Without additives the percentage replacement maximal acceptable is $50 \%$, with additives (adjuvants, cementitious materials...), characteristics are increased. The durability is one of the main points of the concrete's study. A summary of many studies was detailed with highlighting some methods and additives which can improve the durability and long term behavior of the concrete.

\section{References}

1 Domingo-Cabo, A., Lázaro C., López-Gayarre F., Serrano-López, M.A., Serna, P., Castaño-Tabares, J.O.: Creep and shrinkage of recycled aggregate concrete. Constr. Build. Mater.Vol 7 (2009) p. 2545-2553.

2 Gómez-Soberón, J.M.V.: Shrinkage of concrete with replacement of aggregate with recycled concrete aggregate. ACI Spec. Publ. (2002) p.475-496.

3 Hansen,T.C.,Ed.; Taylor and Francis: Recycling of Demolished Concrete and Masonry, Oxfordshire, UK (1992) p.316.

$4 \mathrm{Li}, \mathrm{X}$.: Recycling and reuse of waste concrete in China: Part I. Material behavior of recycled aggregate concret, Resour. Conserv. Recycl. Vol 1-2 (2008) p. 36-44.

5 Rahal, K.: Mechanical properties of concrete with recycled coarse aggregate, Build. Environ.Vol 1 (2007) p. 407-415.

6 Yang, K.H.; Chung, H.S.; Ashour, A.: Influence of type and replacement level of recycled aggregates on concrete properties, ACI Mater.J. Vol 3 (2008) p.289-296.

7 Ajdukiewicz, A.; Kliszczewicz, A.: Influence of recycled aggregates on mechanical properties of HS/HPC, Cem.Concr.Compos. Vol 2 (2002) p.269-279.

8 Abdelgadir Abbas, Gholamreza Fathifazl, O. Burkan Isgor, A. Ghani Razaqpur, Benoit Fournier, Simon Foo: Durability of recycled aggregate concrete designed with equivalent mortar volume method, Cem.Concr.Compos Vol 31 (2009) p.555-563

9 Gonzalez Andreu, Etxeberria Miren: Experimental analysis of properties of high performance recycled aggregate concrete, Construction and Building Materials Vol 52 (2014) p.227-235

10 Lederle, R. E., \& Hiller, J. E.: Reversible shrinkage of concrete made with recycled concrete aggregate and other aggregate types, ACI Materials Journal Vol 110(4) ( 2013) p. 423.

11 Fathifazl, G., \& Razaqpur, A. G.: Creep rheological models for recycled aggregate concrete, ACI Materials Journal Vol 110(2)( 2013) p.115-126.

12 Xiao, J., Li, L., Tam, V. W., \& Li, H.: The state of the art regarding the long-term properties of recycled aggregate concrete, Structural Concrete Vol 15(1) ( 2014) p.3-12.

13 Ryou, J. S., \& Lee, Y. S.: Characterization of recycled coarse aggregate (RCA) via a surface coating method, Inter Jour of Concr Struc and Mater, Vol 8(2) (2014) p. 165-172.

14 Amorim, P., De Brito, J., \& Evangelista, L.: Concrete made with coarse concrete aggregate: Influence of curing on durability, ACI Materials Journal, Vol 109(2012) p. 195 . 
15 Eisa, A.: Properties of concrete incorporating recycled post-consumer environmental wastes, Int Jour of Conc Struc and Mater, Vol 8(3) (2014) p. 251-258. 